\title{
Renal Problems in Early Adult Patients with Turner Syndrome
}

\section{Dong UkYu, M.D. Jae Kyun Ku, M.D. Woo Yeong Chung, M.D.}

Department of Pediatrics, Busan Paik Hospital, College of Medicine, Inje University

\section{Corresponding author:}

Woo Yeong Chung, M.D.

Department of Pediatrics, Busan Paik

Hospital, Inje University

633-165 Kae Kum dong, busanjin ku,

Busan, Korea

Tel: +82-51 890-6280

Fax: +82-51 895-7785

E-mail:chungwy@chol.com

Received: 27 August 2015

Revised: 17 September 2015

Accepted: 6 October 2015
This is an open-access article distributed under the terms of the Creative Commons Attribution Non-Commercial License (http:// creativecommons.org/licenses/bync/3.0/) which permits unrestricted non-commercial use, distribution, and reproduction in any medium, provided the original work is properly cited.
Purpose: This study aimed to evaluate the status of renal function and the presence of urinary abnormalities in early adult patients with Turner syndrome (TS).

Methods: Sixty-three girls with TS, who are attending pediatric endocrine clinics in Busan Paik Hosp., were studied. Urine and blood chemistry tests were performed in every visiting times. Renal ultrasonography was performed in all patients at the initial diagnosis, and intravenous pyelography, DMSA renal scan and renal CT were also performed, if necessary.

Results: Of the 63 patients, the karyotype showed 45,X in 32 (50.8\%) , mosaicism in $22(34.9 \%)$ and structural aberration in $9(14.3 \%)$. The renal function at the latest visit was shown as normal in all patients. Nephrotic syndrome had developed in one patient. Hematuria was observed in seven patients. Renal anomalies were observed in 20 of the $63 \mathrm{TS}$ (31.7\%). Of the $32 \mathrm{TS}$ patients with 45,X karyotype, 13 (40.6\%) had renal anomalies, while these were found in $7(22.6 \%)$ of 31 TS patients with mosaicism/structural aberration. But there was no significant statistical difference between two karyotype groups.

Conclusion: Based on this study, most of the patients with TS do not have any significant problems related to renal function until early adulthood, regardless of renal malformation or hematuria.

Key words: Turner syndrome, Renal anomalies, Renal function, Karyotype

\section{Introduction}

Turner syndrome (TS) is caused by the haplo-insufficiency of some or all genes on the $\mathrm{X}$ chromosomes. This status results from a complete or partial absence of the second $\mathrm{X}$ chromosome or from structural anomalies of one $\mathrm{X}$ chromosome. It is diagnosed when its characteristic clinical features with phenotypic female are noted ${ }^{1)}$. TS is one of the most common sex chromosome disorders and occurs in approximately $1 / 2500$ live-born female births ${ }^{2}$. The most characteristic clinical features of TS are short stature and gonadal dysgenesis, but many organ systems and tissues such as cardiovascular, endocrine, gastrointestinal, renal, neurological, psychiatric, dermatologic, and orthopedic and muscular systems are also affected.

For patients with TS who reach from adolescence to early adulthood, it is essential to make early diagnosis and effective management of the various accompanying problems in order to maintain quality of life. Accordingly, 
there have been a variety of guidelines and treatment principles suggested $^{3-8)}$. The most dangerous and life-threatening problems in adult patients with TS are definitely cardiovascular problems, and already many studies have been reported $^{9-11)}$. However, the studies on renal problems are relatively limited, and there have been few follow-up studies on renal function in particular. Therefore, we assessed renal function in patients with TS who had reached from adolescence to early adulthood.

\section{Materials and Methods}

\section{Subjects}

The study included 63 patients who were over 18 years old at the latest visit among patients who had been diagnosed with TS by a chromosome examination at Inje University, Busan Paik Hospital. The average age of these patients at the latest visit was $23.64 \pm 4.51$ years old, and the mean observation period was $6.09 \pm 4.12$ years. The mean age at the initial diagnosis was $10.49 \pm 4.04$ years old.

\section{Methods}

Urine and blood chemistry tests were performed in all patients for renal function and urine abnormality evaluation. We calculated the estimated glomerular filtration rate (eGFR) in order to evaluate renal function based on the Modification of Diet in Renal Disease (MDRD) equation using serum creatinine concentration and demographic factors. Renal ultrasonography for radiological evaluation of the kidneys was conducted in all patients at the time of initial diagnosis, and it was repeated at least every three years in patients with renal malformation. For renal malformation suspected on the renal ultrasonography, intravenous pyelography was also performed. For some patients who appeared on the renal ultrasonography to require differential diagnosis with renal parenchyma abnormalities or tumors, DMSA renal scan and renal CT scan were conducted.

\section{Statistical analyses}

The study population was divided into two groups according to the cytogenetic findings as classic group (45, $\mathrm{X}$ karyotype) and variant group (mosaicism and structural aberration). Chi-square analysis was used to compare the prevalence of renal malformation by karyotype in the both groups. The P-value of $<0.05$ was considered as statistically significant.

\section{Results}

\section{Cytogenetic findings}

Of the 63 patients, the karyotype showed 45, $\mathrm{X}$ in 32 (50.8\%) patients, variant type in 31 (49.2\%) patients. Of the 31 patients with variant type, 22 patients were mosaicism and 9 patients were structural aberration (Table 1).

\section{Urinary abnormalities and renal function}

The renal function at the latest visit was found to be normal in all patients; the serum BUN level was $9.72 \pm$ $2.60(\mathrm{mg} / \mathrm{dL})$, the creatinine level was $0.64 \pm 0.11(\mathrm{mg} / \mathrm{dL})$, and the eGFR was $125.36 \pm 12.33(\mathrm{~mL} / \mathrm{min} / 1.73 \mathrm{~m} 2)$. Nephrotic syndrome had developed in one patient; he was in remission after use of steroids and has been maintained in remission without relapse. Hematuria was accompanied in seven patients, and it accounted for $11.1 \%$ of the total. Six of those patients were found to have hematuria at the initial diagnosis; the other one developed it during followup. Three of the seven patients with hematuria had renal anomalies, while the other four did not. All cases of hematuria had microscopic hematuria and none of the patients had gross hematuria. In addition, none of the patients showed proteinuria except for one patient with prior nephrotic syndrome.

\section{Incidence of renal anomalies according to the karyotype}

Renal anomalies were observed in 20 of the 63 (31.7\%) patients. Of the 32 patients with 45,X karyotype, 13 (40.6\%) had renal anomalies, while these were found in 7 (22.6\%) of the 31 patients with mosaicism/structural aberration. The incidence of renal anomalies of the patients with 45,X karyotype was higher than that of the patients with mosaicism/structural aberration, but there was no statistical significance $(P>0.05)$.

\section{Type of renal anomalies}

The most frequent type of accompanying renal anoma- 
lies was horseshoe kidney, which occurred in 11 patients, it accounted for about $50 \%$ of all cases of renal malformation. The other types of accompanying renal anomalies are provided in Table 2.

\section{Discussion}

In this study, the renal function of patients with TS who had reached early adulthood presented as normal. There was no relationship with whether any accompanying renal

Table 1. Cytogenetic Findings in 63 Turner syndrome patients

\begin{tabular}{|c|c|}
\hline Karyotype & No. of cases (\%) \\
\hline Classic : $45, X$ & $32(50.8)$ \\
\hline Variant & $31(49.2)$ \\
\hline Mosaicism & 22 \\
\hline $45, X / 46, X X$ & 5 \\
\hline $45, X / 46, X, 1(X q)$ & 5 \\
\hline $45, X / 47, X X X$ & 3 \\
\hline $45, X / 46, X Y$ & 2 \\
\hline $45, \mathrm{X} / 46, \mathrm{X},+\mathrm{mar}$ & 1 \\
\hline $45, X / 47, X Y Y$ & 1 \\
\hline $45, X / 46, X X / 47, X X X$ & 2 \\
\hline $45, X / 46, X$,del(Xq) & 2 \\
\hline $45, X / 46, X, r(X)$ & 1 \\
\hline Structural aberration & 9 \\
\hline $46, X, i(X q)$ & 7 \\
\hline $46, X$,del(Xp) & 1 \\
\hline $46, X, \operatorname{del}(X q)$ & 1 \\
\hline Total & $63(100.0)$ \\
\hline
\end{tabular}

malformation was present. The prevalence of renal anomalies in patients with TS has been reported varies from $24 \%$ to $45 \%$, but it is different depending on the study ${ }^{12,13)}$. The proportion was similarly reported as $43 \%$ in a study in adults ${ }^{14}$. The prevalence of renal anomalies in our study was $31.7 \%$, it was consistent with previous results reported. Development of renal malformation in TS is known to be caused by a defect in the ureteric budding during early stage of pregnancy or by an abnormality in migration of the kidney from the pelvis ${ }^{15)}$. Some studies reported that renal anomalies had a higher frequency in the 45 , X karyotype, but it was revealed to have a weak relationship with karyotype and no statistical significance ${ }^{16,17}$. This study also reported accompanying renal anomalies as $40 \%$ (13/32 patients) in the $45, \mathrm{X}$ karyotype and as $22.6 \%$ (7/31 patients) in the variant type with mosaicism and structural aberration, indicating higher frequency in patients with 45,X karyotype but no statistical significance between both groups.

Horseshoe kidney is one of the most frequent renal anomalies in patients with TS, and it is found in 5-16\% of cases $^{16)}$. The prevalence of horseshoe kidney in patients with TS is much higher than that in the general population, which is $1 / 600-1 / 1800^{18)}$. In our study, horseshoe kidney was the most common type of renal malformation, and it was found in $17.5 \%$ (11/63 patients) of all cases of TS; the other renal anomalies included abnormalities of the renal collecting system and positional anomalies. Although many of these abnormalities do not have any clinical signifi-

Table 2. Type of renal anomalies

\begin{tabular}{|c|c|c|}
\hline Karyotype & Number & Type of renal anomalies \\
\hline \multirow[t]{6}{*}{$45, x$} & 7 & Horseshoe kidney \\
\hline & 1 & Renal agenesis, Rt \\
\hline & 1 & Double pelvocalyces and ureter, Lt \\
\hline & 2 & Bifid renal pelvis, Lt \\
\hline & 1 & Axial deviation of both kidneys, Lt pyeloectasia \\
\hline & 1 & Vertical axis deviation, Lt \\
\hline \multicolumn{3}{|c|}{ Incidence of renal anomaly in $45, X=13 / 32$ (40.6\%) } \\
\hline $45, X / 46, X X$ & 3 & Horseshoe kidney \\
\hline $45, X / 46, X$, del $(X q)$ & 1 & Horseshoe kidney \\
\hline $45, X / 46, X,+$ mar & 1 & Hydronephrosis with incomplete UPJ obstruction, Lt \\
\hline $45, X / 46, X X / 47, X X X$ & 1 & Renal duplication, bilateral \\
\hline 46,X,del(Xp) & 1 & Renal duplication, Lt \\
\hline \multicolumn{3}{|c|}{ Incidence of renal anomaly in mosaicism and structural aberration=7/31 (22.6\%) } \\
\hline
\end{tabular}


cance, some abnormalities may result in an increased risk of hypertension, urinary tract infection, or hydronephrosis, which may lead to chronic renal dysfunction ${ }^{7,16}$.

Most investigators have conducted renal ultrasonography as a method of radiologic assessment of the kidney in patients with TS. Although more renal anomalies were diagnosed by excretory urography in some studies, those reported the cases as malformation were no clinical significance ${ }^{19)}$. Excretory urography was conducted in 17 patients in our study; it helped in the accurate diagnosis of renal malformation in the collecting system, but it had no important effect on renal function.

Growth hormone therapy was conducted in all participating patients. Accordingly, the patients visited the outpatient clinic regularly for growth hormone therapy and related testing; except for two patients, no urinary tract infections were found. Consequently, no evidence could be found that accompanying renal malformation had the potential to increase the frequency of urinary tract infections. Seven patients (11.1\% of all patients) presented with hematuria in this study; six of these were found to have hematuria at the initial diagnosis, and the other one was observed to have it during follow-up. Three of these seven patients with hematuria had accompanying renal malformation, but the other four did not. All cases of hematuria were microscopic hematuria and none of the patients showed gross hematuria. Based on these findings, renal malformation is thought to be one of the causes of hematuria, but the comorbidity potential of glomerular disease cannot be completely ruled out. However no proteinuria was observed in any patients at the time of final follow-up. Therefore, hematuria is not believed to cause significant problems with renal function in early adulthood.

It is rare that patients with TS progress to the end stage of renal failure. Lie et al. ${ }^{20)}$ reported two patients with TS who had dialysis treatment. These patients had received insulin treatment for type II diabetes for more than 10 years and appeared to have had accompanying mental retardation since childhood. Therefore, it was not clear whether or not TS itself had resulted in end stage renal failure. In this study, nephrotic syndrome was observed in one patient; the patient has shown good response to steroids and maintained remission without relapse. The patient was diagnosed with minimal change nephrotic syndrome by the renal biopsy. In fact, there is no clear evidence of increased risk of glomerulonephritis in TS, and only a few cases have been reported in which glomerulonephritis developed in patients with $\mathrm{TS}^{21,22)}$. In South Korea, Han et al. ${ }^{23)}$ reported the first case of focal segmental glomerulosclerosis in a patient with TS. The important point is that in most of the cases, this condition is accompanied by persistent proteinuria and progressive renal dysfunction as well as hematuria.

In conclusion, based on this study, most of the patients with TS do not have any significant problems related to renal function until early adulthood, regardless of renal malformation or hematuria. Despite the relatively high frequency of hematuria in TS, the prognosis is considered to be not much different from that of hematuria in the genetically unaffected patients. Therefore, TS patients with hematuria or renal malformation require continuous followup, and careful attention is required especially if proteinuria or progressive renal dysfunction occurs.

\section{References}

1. Turner HH. A syndrome of infantilism, congenital webbed neck, and cubitus valgus. Endocrinology 1938;23:566-74

2. Nielsen J, Wohlert M. Chromosome abnormalities found among 34,910 newborn children:results from a 13-year incidence study in Arthus, Denmark. Hum Genet 1991;87:81-3

3. Stochholm K, Juul S, Juel K, Naeraa RW, Gravholt CH. Prevalence, incidence, diagnostic delay, and mortality in turner syndrome. J Clin Endocrinol Metab 2006;91:3897-902

4. Sybert VP, McCauley E. Turner's syndrome. N Engl J Med 2004; 351:1227-38

5. Bondy CA, Turner Syndrome Study Group. Care of girls and women with Turner syndrome: a guideline of the Turner syndrome study group. J Clin Endocrinol Metab 2007;92:10-25

6. Davenport ML. Approach to the patients with Turner syndrome. J Clin Endocrinol Metab 2010;95:1487-95

7. Saenger P, Wikland KA, Conway GS, Davenport M, Gravholt CH, Hintz R, et al. Recommendations for the diagnosis and management of Turner syndrome. J Clin Endocrinol Metab 2001;86: 3061-9

8. Kavoussi SK, Christman GM, Smith YR. Healthcare for adolescents with Turner syndrome. J Pediatr Adolesc Gynecol 2006;19:257-65

9. Conway GS, Brand M, Doyle J, Davies MC. How do you monitor the patient with Turner's syndrome in adulthood? Clin Endocrinol(Oxf) 2010;73:696-9 
10. Gawlik A, Malecka-Tendera E. Treatment of Turner's syndrome during transition. Eur J Endocrinol 2014;170:R57-74

11. Naeraa RW, Gravholt CH, Hansen J, Nielsen J, Juul S. Mortality in Turner syndrome. In: Albertsson-Wikland K, Ranke MB, eds. Turner syndrome in a lifespan perspective: research and clinical aspect. Amsterdam: Elsevier;323

12. Bilge I, Kayserili H, Emre S, Nayir A, Sirin A, Tukei T, et al. Frequency of renal malformations in Turner syndrome:analysis of 82 Turkish children. Pediatr Nephrol 2000;14:1111-4

13. Lippe B. Turner syndrome. Endocrinol Metab Clin North Am 1991;20:121-52

14. Sybert VP. The adult patient with Turner syndrome; In Albertsson-Wikland K, Ranke MB, eds. Turner syndrome in a life span perspective: research and clinical aspects. Amsterdam: Elsevier;205-18

15. Elsheikh M, Duinger DB, Conway GS, Wass JA. Turner's syndrome in adulthood. Endocrine Reviews 2002;23:120-40

16. Lippe B, Geffner ME, Dietrich RB, Boechat MN, Kangarloo H. Renal malformations in patients with Turner syndrome:imaging in 141 patients. Pediatrics 1988;82:852-6
17. Flynn MT, Ekstrom L, De Arce M, Costigan C, Hoey HM. Prevalence of renal malformation in Turner syndrome. Pediatr Nephrol 1996;10:498-500

18. Kramer SA, Kelalis PP. Ureteropelvic junction obstruction in children with renal ectopy. J Urol (Paris) 1984;90:331-6.

19. Chang P, Tsau YK, Tsai WY, Tsai WS, Hou JW, Hsiao PH, et al. Renal malformations in children with Turner's syndrome. J Formos Med Assoc 2000;99:796-8

20. Liu WS, Li SY, Yang WC, Chen TW, Lin CC. Dialysis modality for patients with Turner syndrome and renal failure. Perit Dial Int 2012;32: 230-2

21. Goodyer PR. Fong JS, Kaplan BS. Turner's syndrome,46X, del(X)(p11), persistent complement activation and membranoproliferative glomerulonephritis. Am J Nephrol 1982;2:272-5

22. Wattad A, Jain J, Kerrigan J, Youngberg G. Focal segmental glomerulosclerosis and Turner syndrome. Nephron 1998;80:106

23. Han AR, Lee YK, Jung HY, Park JH, Noh JW, Nam ES. A case of focal segmental glomerulosclerosis in turner syndrome Kosin Med J. 2015;30(1):69-72. 